\title{
Lack of Anonymity and Secondary Traumatic Stress in Rural Nurses
}

\author{
Marilyn A. Swan, PhD, $\mathrm{RN}^{1}$ \\ Barbara B. Hobbs Ph.D., RN, NEA, BC 2
}

${ }^{1}$ Associate Professor, College of Allied Health and Nursing, Minnesota State University Mankato, marilyn.swan@mnsu.edu

${ }^{2}$ Professor Emerita, College of Nursing, South Dakota State University, bbarb@rushmore.com

\begin{abstract}
Purpose: The purpose was to determine the prevalence of lack of anonymity (LA) and secondary traumatic stress (STS) among nurses; determine if nurses' LA and STS differ by population density and examine the relationship between lack of anonymity and STS.

Design and Method: A descriptive correlational study examined LA and STS in a random sample of 271 nurses from counties with differing population densities (rural, micropolitan and metropolitan) of a Midwestern US State. A 3-group design was used to examine the relationship between LA and STS in nurses, living and working in these counties. Data on lack of anonymity, secondary trauma and demographics were collected through online questionnaires.

Findings: Rural nurses had a higher prevalence of LA than micropolitan and metropolitan nurses. While the prevalence of STS among rural nurses was higher than either micropolitan or metropolitan nurses; there was no difference in STS among the three population groups. Lack of anonymity and STS were related; however, analysis revealed that LA and STS are inversely correlated, indicating that as LA increases, STS decreases. A majority of rural nurses (90\%) reported living in a rural community prior to their $18^{\text {th }}$ birthday.
\end{abstract}


Conclusions: Rural nurses experience STS at similar rates as their metropolitan and micropolitan counterparts, indicating that population density may not be a factor related to the development of STS. LA appears to have a positive effect on reducing STS in rural nurses.

Clinical Relevance: The study advanced the understanding of LA and STS among nurses who live and work in different population densities. The social support within rural health care facilities and communities may play a role in mitigating the effects of indirect stress.

Keywords: rural, rural nursing, lack of anonymity, traumatic stress

\section{Lack of Anonymity and Secondary Traumatic Stress in Rural Nurses}

Nurses and nursing practice often adapt to the location where a nurse lives and works. As such, nurses working in rural settings are influenced by the unique characteristics of rural health care. Rural health care is associated with being 'small', i.e., small hospitals, small workforces (nurses and providers), small communities, small populations (Lee \& McDonagh, 2013) and lower population densities. Together with the 'small' aspects of rural health care, rural nursing theory identifies common characteristics of rural health, e.g., lack of anonymity, distance between healthcare systems, lower household income, and limited access to health care, that influence nurses and others who live and work in rural settings (Long \& Weinert, 1989). Furthermore, rural nursing is embedded within multiple practice settings: a nursing unit or department, a health care facility, and a community, each with its own population density. Nurses practicing in rural health care commonly report knowing patients and families who are receiving care (Glover, 2019). Relatively unexplored in rural literature is the development of secondary traumatic stress (STS) among nurses who care for people with whom they live and work. Secondary traumatic stress can result from learning second hand about a traumatic or disturbing event to someone a person knows or cares about. The purpose of the study was to determine the prevalence of lack of anonymity 
(LA) and STS among nurses; determine if nurses' LA and STS differ by population density and examine the relationship between lack of anonymity and STS.

\section{Lack of Anonymity}

Nurses who live and work in rural settings experience LA (Lee, 1998; Long \& Weinert, 1989). Rural nursing theorists and rural experts identify LA as a concept unique to rural nursing practice (Hegney, 1996; Lee \& McDonagh, 2013). Rural nurse theory defines rural as "living in sparsely populated areas" (Long \& Weinert, 2018, p.18). Lack of anonymity is defined as "a condition in which one cannot remain nameless or unknown" (Lee, 1998, p. 77), and permeates the life of a rural nurse. Rural nurses describe this experience as 'living in a fish bowl', where the personal life of the nurse is exposed and observable to others (Mills et al., 2010; Rosenthal, 2010).

It is common for rural nurses to provide care to community members with whom they have personal connections (Rosenthal, 2010). Because of these connections, e.g., friendships or family relationships, rural nurses have personal or intimate knowledge of people living and working in the rural community. Additionally, rural nurses encounter current and former patients while out in the community, and they are readily recognized as a nurse (Hegney, 1996). These encounters can blur personal and professional boundaries because rural nurses are often familiar with intimate details of community members (Halverson \& Brownlee, 2010). Similarly, a professional identity is visible to many and can place limits on a rural nurses' ability to maintain a personal, or private self (Swan \& Hobbs, 2017, 2018).

While LA is not well described in urban or largely populated areas, the authors contend that LA may be present in different community environments including urban settings, such as neighborhoods or boroughs, and in online venues. This contention strengthens the connection of LA to population density that is explored in this study. 


\section{Secondary Traumatic Stress}

Secondary Traumatic Stress is a form of indirect traumatic stress and is defined as “...the natural consequent behaviors and emotions resulting from knowing about a traumatizing event experienced by a significant other-the stress resulting from helping or wanting to help a traumatized or suffering person" (Figley, 1995, p. 7). The actual traumatic event happens to another; however, trauma can occur to an individual when hearing about a disturbing event. This type of exposure may result in indirect traumatic stress, often referred to as STS and is attributed to learning about a violent or traumatic event experienced by someone close to you or having repeated exposure to difficult or upsetting experiences that happen to people you know (Figley, 1995). Secondary traumatic stress is a component of posttraumatic stress disorder in the Diagnostic and Statistical Manual of Mental Disorders (American Psychological Association [APA], 2013). Symptoms of secondary traumatic stress mirror those of direct traumatic stress (post-traumatic stress syndrome): thought intrusion, avoidance, and hyperarousal (APA, 2013).

Direct and indirect traumatic stress are part of the human experience (van der Kolk \& McFarlane, 1996/2007); however, little is known about how LA may influence the development of STS in nurses. Research findings suggest that nurses are at high risk for developing STS due to their level of proximity and frequency of potential exposure to traumatic experiences of patients (Figley, 1995; Komachi et al., 2012). Health care workers with the closest proximity to the patient have higher risk of developing STS; part-time workers demonstrate lower levels of STS when compared to full-time workers (Slocum-Gori et al., 2011). The actual prevalence of STS among nurses is unknown. Nursing research on STS has largely focused on nurses working in densely populated areas who work in high stress units or nursing roles. Beck and Gable (2012) found that $63 \%$ of labor and delivery nurses studied reported at least one STS symptom. Similarly, 
Dominguez-Gomez and Rutledge (2009) report that $85 \%$ of emergency room nurses had at least one symptom of STS. These findings suggest nurses are at risk of developing STS from occupational exposure encountered when providing nursing care. Secondary traumatic stress is closely related to burnout and is often reported as a component of compassion fatigue. The risk of STS in rural nurses, who experience LA and have intimate knowledge of people in their community, was not located in the literature reviewed.

\section{Definitions}

For this study, population density refers to the number of people, e.g., nurses, providers, patients, in a given unit of space. Population density was determined by using the Office of Management and Budget's (2013) county designation of metropolitan, micropolitan, and other. Metropolitan counties have a population of 50,000 or more; and, micropolitan counties have a population of at least 10,000, but less than 50,000 (Health Resources and Services Administration, n.d.). The designation of other was used for counties with a population density of less than 10,000 . Those counties were considered rural.

\section{Theoretical Framework}

Social cognitive theory (SCT) and rural nursing theory provided the theoretical framework for the study. Bandura $(1977 ; 1986)$ proposes that reciprocal determinism is the interaction of cognition, behavior and the environment. These three constructs are in relationship with and influence each other. A change in any one construct, will affect the other two. Rural nursing theory concepts can be inserted into the framework of reciprocal determinism. For example, LA is a component of rural nursing theory and also part of the environment. Using this framework, a rural environment, that includes LA, influences a nurse's cognition and behavior. In turn, a nurse adapts to the environmental influence of rural living. When confronted with traumatic stress, a nurse may 
alter their cognition, behavior, and environment to reduce stress (Benight \& Bandura, 2004). This suggests that a nurse's adjustment to stress may reduce the risk of developing STS.

\section{Purpose}

The purpose of this study was to determine the prevalence of LA and STS, determine if there was a difference in STS and to determine if there was a relationship between LA and STS in metropolitan, micropolitan, and rural nurses. Our hypotheses were 1) rural nurses have a higher prevalence of STS related to repeated exposure to traumatic events of patients known to them, and 2) there is a positive relationship between LA and STS in rural nurses.

\section{Methods}

\section{Design}

The study used a descriptive correlational design to examine the relationship between LA and STS in nurses from different population densities. A 3-group design was used to divide nurses into those who lived and worked in metropolitan, micropolitan, and rural locations. The placement into groups was determined by the population density of the county of residence and employment. Nurses who traveled to a different population density area for work were excluded. Study data were collected from a Midwestern plains state in the United States (US). The study procedures were approved for human subject research by the South Dakota State University Institutional Review Board.

\section{Measures}

\section{Lack of Anonymity-10 Instrument (LOAN-10)}

Lack of anonymity is measured using a 10-item, self-report instrument (Swan, 2015). The 5point Likert scale rates agreement with items, ranging from strongly agree (1) to strongly disagree (5). Total point range is 5-50 (Swan, 2015). Based on participant responses, a cumulative score is 
calculated. Scores of 10-25 indicate the individual may be experiencing LA; scores of 26-34 are indeterminate; and scores of 35-50 indicate the individual may be experiencing greater anonymity. For this study, the instrument's Cronbach's alpha was .863, indicating internal consistency.

\section{Secondary Traumatic Stress Subscale}

Secondary traumatic stress was a factor of the Compassion Fatigue-Short Scale-Adapted (CF-SS-A). Burnout (8-item) and STS (5-item) are measured within the 13-item, self-report screening instrument adapted from the CF-SS (Bride et al., 2007; Adams et al., 2006). The original CF-SS was developed for use with social workers; we were unable to locate a study demonstrating the use of CF-SS with a nursing population. Therefore, a convenience sample of registered nurses, familiar with rural nursing, was asked to provide expert review. Based on registered nurse feedback, CF-SS statements were modified to ensure clarity for the target nursing population. The modified instrument was renamed the CF-SS-A.

The CF-SS-A 10-point Likert scale rates occurrence of events, ranging from never or rarely (1) to very often (10) (Adams et al., 2008). The two subscale scores are summed separately with possible scores of 8-80 (burnout) and 5-50 (STS) respectfully. A higher score (30 or more) on the burnout subscale indicates burnout may be present, and clinical evaluation may be warranted. Likewise, a score of 15 or higher on the STS subscale indicates STS may be present and clinical evaluation may be warranted (Boscarino et al., 2010). Adams et al. reported an overall instrument Cronbach's alpha of .90 , with Cronbach's alpha of .90 for burnout and .80 for STS (2006). For this study, the Cronbach's alpha for the overall instrument was .92. The subscale Cronbach's alpha was .89 for burnout, and .85 for STS.

\section{Demographics}


The demographic data included information pertinent to understanding LA and STS, and to adequately describe the sample. Demographic information included age, gender, ethnicity, years licensed as a nurse, current practice setting, county of employment, and whether or not the participant lived in a rural community prior to their 18th birthday, a factor associated with adults living and working in rural areas.

\section{Study Procedures}

\section{Sample}

Study participants needed to be 1) 19 years of age or older, 2) licensed as a registered nurse, 2) working a minimum of 20 hours per week, and 4) employed at their current employer for at least two years. The inclusion criteria were selected to ensure that participating nurses had enough opportunity to experience LA or STS in a practice setting. Additionally, requiring two years of nursing practice reduced the confounding variable of new nurses transitioning into practice.

A county list from a Midwestern state was developed, with population designated as metropolitan, micropolitan, or rural, and subsequently provided to the Board of Nursing. The Board of Nursing was asked to randomly select 500 registered nurse names for each of the county population designations from the state's database. This number ensured each population density would be adequately represented in the study. In total, the Board of Nursing provided a random sample of 1500 registered nurses as prospective participants. The prospective participant list included each registered nurse's name, email, home address, and county of residence. The list was reviewed to ensure that each county designation was represented as requested.

\section{Data Collection}

A 5-contact method described by Dillman et al. (2009), modified for an online distribution, was used. A pre-notice letter, introducing the study and inviting their participation in the online 
questionnaire that would be sent to their email address, was sent to the homes of the selected registered nurses. The study questionnaire was copied to Qualtrics ${ }^{\mathrm{TM}}$ software for online distribution. Seven days after the pre-notice letter mailing, an email was sent to the registered nurses email address. The online questionnaire included questions on the inclusion criteria, and a consent form for study participation. Following consent, participating registered nurses completed online versions of the LOAN-10, CF-SS-A, and demographic information. Seven days after the initial email, a thank-you email containing the link to the study questionnaire was sent to prospective participants. After seven days, a fourth contact was made by email with a link to the online questionnaire. The final contact was sent seven days after the fourth contact. The survey was then left open for one week and then closed.

The study procedures considered how to promote the highest response rate possible. The prenotice letter introduced the study and alerted prospective participants to look for the study email. While the pre-notice letter incurred expense, its purpose was to prevent the study email from being deleted before being viewed (Dillman et al., 2009). Emails were concisely written to communicate the study instructions clearly for quick viewing (Dillman et al., 2009). In addition, emails were sent out first thing in the morning allowing the emails to be viewed early in the day, thus promoting participation (Dillman et al., 2009). The use of the Qualtrics ${ }^{\mathrm{TM}}$ software allowed for the development of an email distribution list for the 1500 randomly selected registered nurses. The use of a distribution list allowed us to personalize the email by inserting the nurse's name into the email salutation (Dillman et al., 2009). Another benefit of using a distribution list is the link was tied to the email to which it was sent; this means that if the email was forwarded, the survey could not be completed. This provided assurance that only the randomly selected nurses completed the survey. 


\section{Data Analysis}

Descriptive statistics, including group and aggregate totals, frequency distribution, measures of central tendency, range, and variance were used to report on CF-SS-A. A one-way ANOVA was used to determine differences in STS scores among metropolitan, micropolitan, and rural nurses. A Pearson correlation coefficient was used to describe the relationship between LA and STS by group and aggregate total.

\section{Results}

A total of 340 nurses completed the questionnaires, of which $80 \%(\mathrm{~N}=271)$ met the threegroup study design requirements; metropolitan $(n=113)$ nurses had the highest response rate, followed by micropolitan $(\mathrm{n}=77)$, and rural $(\mathrm{n}=81)$. The study sample was predominately White (94.5\%) and female (91\%). The mean age was 44.5 years. Metropolitan nurses had fewer years of licensure $(M=16, S D=11.39)$ than $\operatorname{rural}(M=17.5, S D=11.87)$ and micropolitan $(M=18.3, S D$ $=12.19)$ nurses. Acute care was the most common practice setting (44.6\%). A majority of rural nurses $(90 \%)$ indicated that they had lived in a rural community prior to their 18 th birthday followed by micropolitan then metropolitan nurses (see Table 1).

\section{Table 1}

Live in a Rural Community Prior to $18^{\text {th }}$ Birthday

\begin{tabular}{ccccccc}
\hline & \multicolumn{2}{c}{ Metropolitan } & \multicolumn{2}{c}{ Micropolitan } & \multicolumn{2}{c}{ Rural } \\
\hline & Frequency & Percent & Frequency & Percent & Frequency & Percent \\
\hline Yes & 56 & 49.6 & 57 & 74.0 & 73 & 90.1 \\
No & 57 & 50.4 & 26 & 26.0 & 8 & 9.9 \\
\hline
\end{tabular}

Data analysis revealed a higher prevalence $(85.2 \%)$ of LA among rural nurses than was indicated by micropolitan or metropolitan nurses (see Table 2). 


\section{Table 2}

Loan-10 Scores by County Group

\begin{tabular}{lcccccc}
\hline & \multicolumn{2}{c}{ Metropolitan } & \multicolumn{2}{c}{ Micropolitan } & \multicolumn{2}{c}{ Rural } \\
\hline & Frequency & Percent & Frequency & Percent & Frequency & Percent \\
\hline LA & 15 & 13.3 & 46 & 59.7 & 69 & 85.2 \\
Indeterminate & 44 & 39.0 & 26 & 33.8 & 10 & 12.3 \\
Anonymity & 54 & 47.7 & 5 & 6.5 & 2 & 2.5 \\
\hline
\end{tabular}

For the total sample, $39 \%$ of the registered nurses had scores indicating STS may be

present. The prevalence of STS was highest in rural nurses and lowest in micropolitan nurses (see Table 3 and 4).

Table 3

Frequency of STS (Subscale) by County Group

\begin{tabular}{lcccccc}
\hline & \multicolumn{2}{c}{ Metropolitan } & \multicolumn{2}{c}{ Micropolitan } & \multicolumn{2}{c}{ Rural } \\
\hline & Frequency & Percent & Frequency & Percent & Frequency & Percent \\
\hline STS Present & 42 & 37.2 & 25 & 32.5 & 39 & 48.1 \\
No STS & 71 & 62.8 & 52 & 67.5 & 42 & 51.9 \\
\hline
\end{tabular}

\section{Table 4}

Scores for STS (Subscale) by County Group

\begin{tabular}{lcccc}
\hline Place & $n$ & Range & $M(S D)$ & $95 \%$ CI \\
\hline Metropolitan & 113 & $5-50$ & $15.26(10.26)$ & {$[13.34,17.17]$} \\
Micropolitan & 77 & $5-48$ & $13.25(7.84)$ & {$[11.47,15.03]$} \\
Rural & 81 & $5-41$ & $16.44(8.92)$ & {$[14.47,18.42]$}
\end{tabular}

Note. $N=271 . M=$ mean. $S D=$ standard deviation. $\mathrm{CI}=$ confidence interval.

A one-way ANOVA was performed and indicated there was no significant difference in STS among metropolitan, micropolitan, and rural nurses. Population density was not a factor related to the development of STS for this study (see Table 5). 


\section{Table 5}

Analysis of Variance of STS for Metropolitan, Micropolitan and Rural Nurses

\begin{tabular}{lccccc}
\hline & $S S$ & $d f$ & $M S$ & $F$ & $p$ \\
\hline Between Groups & 412.68 & 2 & 206.34 & 2.42 & .091 \\
Within Groups & 22819.87 & 268 & 85.15 & & \\
Total & 23232.55 & 270 & & & \\
\hline
\end{tabular}

A Pearson product-moment correlation coefficient was calculated on the LA and STS data and revealed a significant negative correlation between LA and STS $(r=-.126, p=.038)$ for the entire sample of registered nurses. As the LA increased, STS decreased. When calculated for each of the 3-groups, however, no significant relationship was found between LA and STS in metropolitan $(r=-.153, p=.105, n=113)$, micropolitan $(r=-.172, p=.135, n=77)$, and rural $(r$ $=-.160, p=.153, n=81)$ nurses. The loss of significance suggests the sample size was not large enough to maintain statistical power (Portney \& Watkins, 2009).

\section{Discussion}

The purpose of the study was threefold: To examine the frequency of lack of anonymity (LA) and STS among nurses. To determine if nurses' LA and STS differ by population density and to understand the relationship between LA and STS in nurses who lived in different locations.

As expected, rural nurses experience more LA than their micropolitan and metropolitan counterparts. Although LA is described in the literature, this study is believed to be the first to measure, or quantify, LA in a population. The prevalence of LA in this study sample is consistent with descriptions in both rural nursing practice research literature and rural nursing theory (Hegney, 1996; Lee \& McDonagh, 2013).

Likewise, findings in this study support previous research on the prevalence of STS in nursing. There was, however, no difference in the development of STS based on population density; thus, the hypothesis that rural nurses would experience higher STS was not supported. 
Rural nurses experienced STS at rates similar to their micropolitan and metropolitan counterparts. The overall prevalence of STS in this sample of nurses is consistent with, if not lower, than other studies. Studies of STS commonly use a convenience sample from a specific unit or institution and use a variety of instruments. The randomized sample utilized in this study further supports previous findings related to prevalence of STS in nurses. In this study, almost $40 \%$ of the overall sample and close to one-half of the rural nurses had scores indicating STS may be present. STS is affecting a large portion of the nursing workforce, particularly the rural workforce. This is an issue that requires further study to fully understand STS development and explore ways to mitigate its effects.

The inverse relationship between the study variables of LA and STS in the rural nurse group suggests LA may have a positive effect on reducing STS in rural nurses. More research is needed to understand the relationship between these two variables as LA is generally considered a negative attribute in rural practice (Hegney, 1996). Social and workplace support in rural areas differs from metropolitan environments. However, the interconnectedness of rural health care communities may provide a social and workplace support system across the institution (Hunsberger et al., 2009). As such, support a rural nurse receives may cross professions, inside and outside of the work environment.

As described in the literature, social support is linked with lower incidence of psychiatric illness and may be an independent mediator in the development and recovery from STS (Shoji et al., 2014; Stansfeld et al., 1999; Regehr et al., 2013). Similarly, Brown et al. (2018) found that change fatigue, a form of stress, occurs less frequently in nurses who work in acute care facilities with fewer beds (i.e. smaller facilities). Brown et al.'s recent findings suggest that social support in rural health care and stress are linked in some way. The relational quality of both theoretical 
concepts suggests that the interdependent, interprofessional social support in rural environments requires closer examination. These findings highlight the need for future research on the mechanism of influence between environmental context and the inherent social and workplace support in rural health care facilities and how this influences rural nursing practice.

A vast majority of rural nurses had childhood experiences with rural living before their 18th birthday and were more likely to stay in a rural location. Research evidence supports that a predictive relationship exists between having a rural background and choosing to work in a rural location (Cosgrave et al., 2019; Woloschuk et al., 2005). This study did not determine if the childhood experiences occurred within the rural community in which the nurse lives and works; however, the study findings appear to support rural workforce recruitment practices of recruiting within rural communities and growing your own (MacPhee \& Scott, 2002). The connection between rural childhood experiences and choosing to live and work in a rural community as an adult needs further research.

\section{Limitations}

The findings from this study are generalized to a Midwestern state in the US. The study inclusion criteria requiring at least two years of nursing experience, reduced the sample size. The small sample size within the 3-group design affected the statistical power to identify significant differences. Lack of anonymity is a broad concept that may have confounding variables that are not well understood; thus, bias may have been present.

\section{Conclusion}


Nurses live and work in areas with different population densities. This study showed rural nurses are more likely to experience lack of anonymity than nurses working in more densely populated areas. The prevalence of STS for all nurses is considerable and warrants further investigation. No positive relationship between LA and STS was found, however, additional research is needed to further understand LA within rural nursing environments.

\section{References}

Adams, R. E., Figley, C. R., \& Boscarino, J. A. (2006). Compassion fatigue and psychological distress among social workers: A validation study. American Journal of Orthopsychiatry, 76(1), 103-108. https://doi.org/10.1037/0002-9432.76.1.103

Adams, R. E., Figley, C. R., \& Boscarino, J. A. (2008). The compassion fatigue scale: Its use with social workers following urban disaster. Research on Social Work Practice, 18(3), 238-250. https://doi.org/10.1177/1049731507310190

American Psychological Association (2013). Diagnostic and statistical manual of mental disorders (5th ed.). https://doi.org/10.1176/appi.books.9780890425596.991543

Bandura, A. (1977). Social learning theory. Prentice-Hall, Inc.

Bandura, A. (1986). Social foundations of thought \& action. A social cognitive theory. PrenticeHall, Inc.

Beck, C. T., \& Gable, R. K. (2012). A mixed methods study of secondary traumatic stress in labor and delivery nurses. Journal of Obstetric, Gynecologic \& Neonatal Nursing, 41(6), 747-760. https://doi.org/10.1111/j.1552-6909.2012.01386.x

Benight, C. C., \& Bandura, A. (2004). Social cognitive theory of posttraumatic recovery: The role of perceived self-efficacy. Behaviour Research and Therapy, 42(10), 1129-1148. https://doi.org/10.1016/j.brat.2003.08.008 
Boscarino, J. A., Adams, R. E., \& Figley, C. R. (2010). Secondary trauma issues of psychiatrists. Psychiatric Times, 27(11), 1-6. https://www.psychiatrictimes.com/view/secondary-trauma$\underline{\text { issues-psychiatrists }}$

Bride, B. E., Radey, M., \& Figley, C. R. (2007). Measuring compassion fatigue. Clinical Social Work Journal, 35, 155-163. https://doi.org/10.1007/s10615-007-0091-7

Brown, R., Wey, H., \& Foland, K. (2018). The relationship among change fatigue, resilience, and job satisfaction of hospital staff nurses. Journal of Nursing Scholarship, 50(3), 306-313. https://doi.org/10.1111/jnu.12373

Cosgrave, C., Malatzky, C., \& Gillespie, J. (2019). Social determinants of rural health workforce retention: A scoping review. International Journal of Environmental Research \& Public Health, 16(3), 314. https://doi.org/10.3390/ijerph16030314

Dillman, D. A., Smyth, J. D., \& Christian, L. M. (2009). Internet, mail, and mixed-mode surveys: The tailored design method (3rd ed.). John Wiley \& Sons, Inc.

Dominguez-Gomez, E., \& Rutledge, D. N. (2009). Prevalence of secondary traumatic stress among emergency nurses. Journal of Emergency Nursing, 35(3), 199-204. https://doi.org/10.1016/ j.jen.2008.05.003

Figley, C. R. (1995). Compassion fatigue as secondary traumatic stress disorder: An overview. In C. Figley (Ed.), Compassion fatigue: Coping with secondary traumatic stress disorder (pp. 1-20). Brunner/Mazel, Publishers.

Glover, J. J. (2019). Rural health care and an ethics of familiarity. Narrative Inquiry in Bioethics, 9(2), 113-119. https://doi.org/10.1353/nib.2019.0036 
Halverson, G., \& Brownlee, K. (2010). Managing ethical considerations around dual relationships in small rural and remote Canadian communities. International Social Work, 53(2), 247-260. https://doi.org/10.1177/0020872809355386

Health Resources and Services Administration (n.d.). Defining the rural population. http://www.hrsa.gov/ruralhealth/policy/definition_of_rural.html

Hegney, D. (1996). The status of rural nursing in Australia: A review. The Australian Journal of Rural Health, 4(1), 1-10. https://doi.org/10.1111/j.1440-1584.1996.tb00180.x

Hunsberger, M., Baumann, A., Blythe, J., \& Crea, M. (2009). Sustaining the rural workforce: Nursing perspectives on worklife challenges. The Journal of Rural Health, 25(1), 17-25. https://doi.org/10.1111/j.1748-0361.2009.00194.x

Komachi, M. H., Kamibeppu, K., Nishi, D., \& Matsuoka, Y. (2012). Secondary traumatic stress and associated factors among Japanese nurses working in hospitals. International Journal of Nursing Practice, 18(2), 155-163. https://doi.org/10.1111/j.1440-172X.2012.02014.X

Lee, H. (1998). Lack of anonymity. In H. Lee (Ed.), Conceptual basis for rural nursing (1st ed., pp. 76-88). Springer Publishing.

Lee, H. J., \& McDonagh, M. K. (2013). Updating the rural nursing theory base. In C. Winters (Ed.), Rural nursing concepts, theory, and practice (4th ed., pp. 15-33). Springer Publishing.

Long, K. A., \& Weinert, C. (2018). Rural nursing: Developing the theory base. In C. A. Winters \& H. J. Lee (Eds.), Rural nursing: Concepts, theory and practice (5th ed., pp. 17-30). Springer Publishing

Long, K. A., \& Weinert, C. (1989). Rural nursing: Developing the theory base. Scholarly Inquiry for Nursing Practice, 3(2), 113-127. 
MacPhee, M., \& Scott, J. (2002). The role of social support networks for rural hospital nurses. Journal of Nursing Administration, 32(5), 264-272. https://doi.org/10.1097/00005110$\underline{200205000-00006}$

Mills, J., Birks, M., \& Hegney, D. (2010). The status of rural nursing in Australia: 12 years on. Collegian, 17(1), 30-37. https://doi.org/10.1016/j.colegn.2009.09.001

Office of Management and Budget (2013). Revised delineations of metropolitan statistical areas, micropolitan statistical data, and combined statistical areas, and guidance on uses of these delineations of these areas. https:/www.whitehouse.gov/sites/whitehouse.gov/files/ omb/bulletins/2013/b13-01.pdf

Portney, L. G., \& Watkins, M. P. (2009). Foundations of clinical research applications to practice (3rd ed.). Pearson Education.

Regehr, C., LeBlanc, V. R., Barath, I., Balch, J., \& Birze, A. (2013). Predictors of physiological stress and psychological distress in police communicators. Police Practice and Research, 14(6), 451-463. https://doi.org/10.1080/15614263.2012.736718

Rosenthal, K. A. (2010). The rural nursing generalist in the acute care setting: Flowing like a river. In C. Winters \& H. Lee (Eds.), Rural nursing concepts, theory and practice (3rd ed., pp. 269298). Springer Publishing.

Shoji, K., Bock, J., Cieslak, R., Zukowska, K., Luszcynska, A., \& Benight, C. C. (2014). Cultivating secondary traumatic growth among health care workers: The role of social support and self-efficacy. Journal of Clinical Psychology, 70(9), 831-846 https://doi.org/10.1002/jclp.22070

Slocum-Gori, S., Hemsworth, D., Chan, W. W., Carson, A., \& Kazanjian, A. (2011). Understanding compassion satisfaction, compassion fatigue and burnout: A survey of the 
hospice palliative care workforce. Palliative Medicine, 27(2), 172-178. https://doi.org/10.1177/0269216311431311

Stansfeld, S. A., Fuhrer, R., Shipley, M. J., \& Marmot, M. G. (1999). Work characteristics predict psychiatric disorder: Prospective results from the Whitehall II study. Occupational and Environmental Medicine, 56, 302-307. http://dx.doi.org/10.1136/oem.56.5.302

Swan, M. A., \& Hobbs, B. B. (2017). Concept analysis: Lack of anonymity. Journal of Advanced Nursing, 75(5), 1075-1084. https://doi.org/10.1111/jan.13236

Swan, M. A., \& Hobbs, B. B. (2018). Lack of Anonymity: Changes to the $21^{\text {st }}$ Century. In C.A. Winters \& H.J. Lee (Eds.). Rural nursing: Concepts, theory and practice ( $5^{\text {th }}$ ed., pp 79 -92). Springer.

van der Kolk, B. A., \& McFarlane, A. C. (1996/2007). The black hole of trauma. In B. van der Kolk, A. McFarlane, \& L. Weisaeth (Eds.), Traumatic stress. The effects of overwhelming experience on mind, body, and society (pp. 3-23). The Guilford Press.

Woloschuk, W., Crutcher, R., \& Szafran, O. (2005). Preparedness for rural community leadership and its impact on practice location of family medicine graduates. Australian Journal of Rural Health, 13(1), 3-7. https://doi.org/10.1111/j.1440-1854.2004.00637.x 